Nucl eot i de sequences of repti l e cal ci toni ns: Thei $r$ hi gh homl ogy to chi cken cal ci toni $n$

\begin{tabular}{|l|l|}
\hline 著者 & $\begin{array}{l}\text { Suzuki Nobuo, Eguchi C. , H rai T. , Sasayana } \\
\text { Yui chi }\end{array}$ \\
\hline $\begin{array}{l}\text { j our nal or } \\
\text { publ i cat i on ti t l e }\end{array}$ & Zool ogi cal Sci ence \\
\hline vol ume & 14 \\
\hline number & 5 \\
\hline page r ange & $833-836$ \\
\hline year & $1997-10-01$ \\
\hline URL & ht t p: //hdl . handl e. net /2297/10561 \\
\hline
\end{tabular}




\title{
Nucleotide Sequences of Reptile Calcitonins: Their High Homology to Chicken Calcitonin
}

\author{
Nobuo Suzuki ${ }^{1}$, Chikashi Eguchi ${ }^{2}$, Toshiaki Hirai ${ }^{3}$ \\ and Yuichi Sasayama ${ }^{1 *}$ \\ ${ }^{1}$ Noto Marine Laboratory, Faculty of Science, Kanazawa University, \\ Uchiura, Ishikawa 927-05, Japan \\ ${ }^{2}$ Kato Cytoprotein Network Project, Sagami Chemical Research Center, \\ Sagamihara, Kanagawa 229, Japan \\ ${ }^{3}$ Department of Biosciences, Teikyo University of Science and Technology, \\ Uénohara 2525, Yamanashi 409-01, Japan
}

\begin{abstract}
The calcitonin genes of four species of reptiles (Reeve's turtle, rat snake, grass lizard, and spectacled caiman) were amplified from the genomic DNA, as well as from the mRNA of the ultimobranchial glands of the former three species, by the polymerase chain reaction (PCR) method, and were sequenced. Among several primer sets, only one primer set synthesized from the chicken calcitonin gene was compatible with those of the reptiles. The nucleotide sequences of the reptile calcitonin genes were highly homologous with that of chicken calcitonin ( $100 \%$ for turtle, $99 \%$ for caiman, $96 \%$ for lizard and $93 \%$ for snake). The products amplified from mRNA by the RT-PCR method matched completely those from genomic DNA in the turtle, snake and lizard.
\end{abstract}

\section{INTRODUCTION}

Calcitonin, a hypocalcemic hormone composed of 32 amino acid residues, is secreted from the C-cells of the thyroid gland in mammals and from the ultimobranchial glands in non-mammals (Copp et al., 1970). The primary structure of calcitonin has been determined in 13 species of animals (Sasayama et al., 1993). Those calcitonins have been classified into four lineages according to the similarity of amino acid sequences: human lineage (human, rabbit and rat); pig lineage (pig, cattle, dog and sheep); bony fish lineage (salmon, eel, goldfish, sardine and chicken); cartilaginous fish lineage (stingray). Recently, however, we clarified the sequence of amino acid residues of bulfrog calcitonin (Yoshida et al., 1997), which belongs to a fifth lineage. Therefore, only the sequence of calcitonin of reptiles, phylogenetically located between birds and amphibians, has not been reported.

Reptiles are the first vertebrates to be completely independent of the water environment by developing an eggshell and an amnion. This fact shows that reptiles can perform calcium metabolism of the terrestrial type, different from that of the amphibians. In reptiles, however, the role of calcitonin in calcium metabolism has not been clarified. Thus, information on the primary structure of reptile calcitonin is of interest also from the viewpoint of biological function. This study may con-

* Corresponding author: Tel. +81-768-74-1151; FAX. +81-768-74-1644. tribute to our knowledge of the molecular evolution of calcitonin.

\section{MATERIALS AND METHODS}

\section{Preparation of genomic DNA and RNA}

Spectacled caiman (Caiman crocodilus) was purchased through a commercial source. Experimental use of this species is not contrary to the Washington treaty. Rat snake (Elaphe climacophora), grass lizard (Takydromus tachydromoides) and Reeves's turtle (Geoclemys reevesil) were caught around our laboratory in Ogi district of Uchiura Town, Ishikawa Prefecture. Genomic DNA was isolated from the liver using a genomic DNA isolation kit (Funakoshi, Tokyo).

Tissue (20-100 mg) containing ultimobranchial glands was dissected out from lizard, turtle and snake using a binocular dissecting microscope, and was immediately frozen in liquid nitrogen. These samples were stored at $-80^{\circ} \mathrm{C}$ until analysis. The total RNA was obtained using an isolation kit (Nippon Gene, Toyama).

\section{Polymerase chain reaction (PCR)}

Figure $1 \mathrm{~A}$ shows the genomic structure of the human calcitonin gene and the location of the primers. Three primers $(C-1, C-2, C-3$ primers) from $3^{\prime}$ region of 30 mer were synthesized according to the nucleotide sequences of human (Steenbergh et al., 1986), salmon (Pöschl et al., 1987) and chicken (Lasmoles et al., 1985) calcitonins (Fig. 1B). As a 5' primer, a mixture of 24 mer containing 64 sequence combinations from the consensus of the three species was synthesized (N-1 primer) (Fig. 1B). Therefore, the region which should be amplified is $96 \mathrm{bp}$ of the calcitonin gene and $1 \mathrm{bp}$ just prior to the gene (Fig. 1A).

One $\mu \mathrm{g}$ each of genomic DNA was subjected to PCR. The PCR was performed for $30-45$ cycles of $30-60 \mathrm{sec}$ at $95^{\circ} \mathrm{C}, 30 \mathrm{sec}$ at $47-$ $55^{\circ} \mathrm{C}$, and $30-60 \mathrm{sec}$ at $72^{\circ} \mathrm{C}$ in $20 \mu \mathrm{l}$ of a solution containing $50 \mathrm{mM}$ 


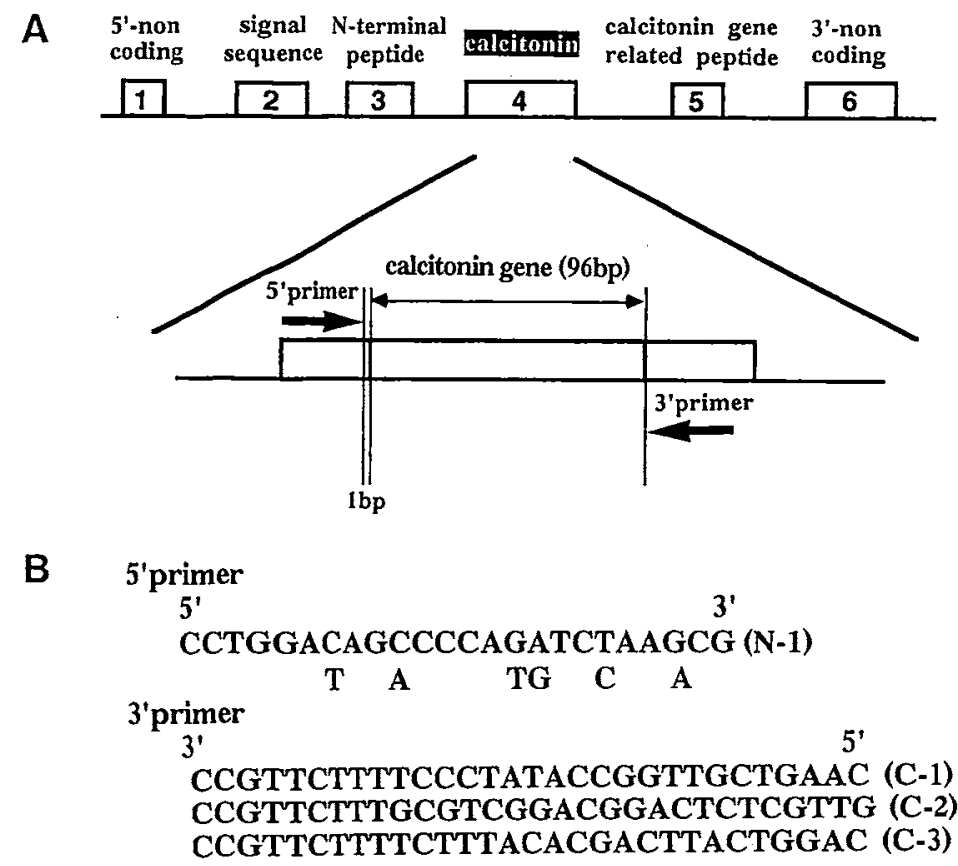

Fig. 1. (A) Genomic gene structure of human calcitonin gene. Calcitonin gene is composed of six exons. Exon 4 encodes mature calcitonin (96 bp). $5^{\prime}$ primer and $3^{\prime}$ primer for PCR were synthesized up- and down-stream of mature calcitonin, respectively. (B) Primers designed for PCR method. Three primers (C-1, C-2, C-3 primers) from $3^{\prime}$ region of 30 mer were synthesized according to the nucleotide sequences of human, salmon and chicken calcitonins. As a $5^{\prime}$ primer, a mixture of 24 mer ( $\mathrm{N}-1$ primer) containing 64 sequence combinations from human, salmon and chicken calcitonin gene was synthesized.

$\mathrm{KCl}, 10 \mathrm{mM}$ Tris- $\mathrm{HCl}(\mathrm{pH} 8.8), 2.5-8.5 \mathrm{mM} \mathrm{MgCl}_{2}, 1 \%$ Triton $\mathrm{X}-100$, $250-500 \mu \mathrm{M}$ of dNTPs, 1 unit of Taq polymerase (Nippon Gene, Toyama) and $0.5 \mu \mathrm{M}$ of each of the primers. An aliquot of the amplified product containing $8 \mu \mathrm{l}$ of the solution was analyzed on $3 \%$ NuSieve GTG agarose gel (FMC Bioproducts, Rockland).

\section{Reverse-transcriptase PCR (RT-PCR)}

An RT-PCR was made by the method of Iwami et al. (1996). This method was useful to prevent contamination of genomic DNA. One $\mu \mathrm{g}$ of total RNA was reverse-transcribed in $20 \mu \mathrm{l}$ of solution composed of $10 \mathrm{mM}$ Tris- $\mathrm{HCl}(\mathrm{pH} 8.3), 50 \mathrm{mM} \mathrm{KCl}, 5 \mathrm{mM} \mathrm{MgCl}_{2}, 1 \mathrm{mM}$ of dNTPs, 0.5 unit $/ \mu$ l of RAV-2 reverse transcriptase (Takara, Kyoto) and $1 \mu$ l of Oligotex-dT 30 Super (Takara, Kyoto). This solution was incubated for $60 \mathrm{~min}$ at $42^{\circ} \mathrm{C}$, boiled for $5 \mathrm{~min}$ and immediately chilled on ice. By this treatment, cDNA was synthesized and bonded to the latex. This cDNA bound to the latex was separated from the reaction mixture by centrifugation at $15,000 \mathrm{rpm}$ for $5 \mathrm{~min}$ at $4^{\circ} \mathrm{C}$, and was washed twice with $200 \mu$ of TE solution ( $10 \mathrm{mM}$ Tris- $\mathrm{HCl}(\mathrm{pH} 8.0$ ), 1 $\mathrm{mM}$ EDTA). The washed latex was suspended in $100 \mu \mathrm{l}$ of solution composed of $10 \mathrm{mM}$ Tris- $\mathrm{HCl}\left(\mathrm{pH} \mathrm{8.8)}, 50 \mathrm{mM} \mathrm{KCl}, 2.5 \mathrm{mM} \mathrm{MgCl}_{2}, 75\right.$ $\mu \mathrm{M}$ of each dNTP in the presence of $0.5 \mu \mathrm{M}$ of $\mathrm{N}-1$ primer and the $\mathrm{C}$ 3 primer. One $\mu \mathrm{g}$ of cDNA supported by the latex was subjected to $\mathrm{PCR}$ as described in the previous section.

\section{Cloning and sequencing of the PCR product}

As the positive control of PCR, salmon calcitonin gene was amplified with the primers of $\mathrm{N}-1$ and $\mathrm{C}-2$ under the same condition. The DNA fragment amplified was composed of $151 \mathrm{bp}$, since the calcitonin region is $96 \mathrm{bp}$, primer regions $54 \mathrm{bp}$ and $1 \mathrm{bp}$ just prior to the calcitonin. After electrophoresis, a band of the same size as the 151 bp was eluted in $300 \mu$ of TE solution at $70^{\circ} \mathrm{C}$, followed by two times of phenol extraction. The purified DNA fragments were ligated into pT7 Blue vector (Takara, Kyoto). After screening, the nucleotide se- quence was determined by a DNA sequencer (Model 373S, Applied Biosystems) using the dideoxynucleotide chain terminal procedure with T7 primer for the vector.

\section{RESULTS}

Among primers applied, the ones synthesized on the bases of nucleotide sequences of human calcitonin (C-1) and salmon calcitonin (C-2) could not amplify the reptile calcitonin gene. However, when chicken primer (C-3) was used, in all four species of reptiles, the portion of $96 \mathrm{bp}$ out of the probable $151 \mathrm{bp}$, which codes a mature hormone composed of 32 amino acid residues, was amplified from genomic DNA. The nucleotide sequences of those calcitonins were highly homologous to that of chicken calcitonin. Furthermore, the nucleotide sequence obtained from RT-PCR performed in snake, lizard and turtle coincided completely with that of genomic DNA in each species. Figure 2 summarizes the results. In this study, in one $P C R$ performance at least four clones were sequenced and we confirmed that their nucleotide sequences coincide completely. In caiman (sequence identity to chicken, $99 \%$ ), only the 24th nucleotide for the 8 th amino acid residue differs, although the substitution is silent. In snake (sequence identity, 93\%), seven nucleotides differ at'positions $8,9,15,54$, 63,90 and 93 . Although the substitution at positions 8 and 9 resulted in different amino acid residue in the 3rd amino acid residue, that is, Ser in chicken and Asn in snake, other substitutions are silent. In lizard (sequence identity, 96\%), although 
chicken 5'-IGT GCC AGT CTG AGT ACT IGT GTG CTG GGC AAA CTG ICI CAA GAA ITG CAC AAA YTG CAA ACT TAC CCT CGT ACT GAC GTC GGG GCI GGA ACT CCT-3. turtle $\quad$-.. - -

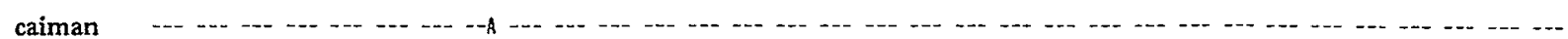

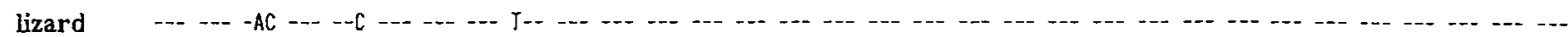

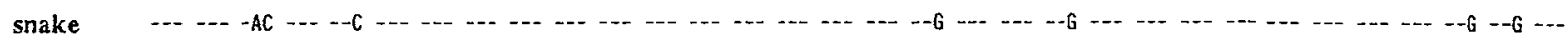

chicken Cys Ala Ser Leu Ser Thr Cys Val Leu Gly lys Leu Ser Gla Glu Leu his Lys Leu Gln Thr Tyr Pro Arg Thr Asp Val gly Ala Gly Thr Pro

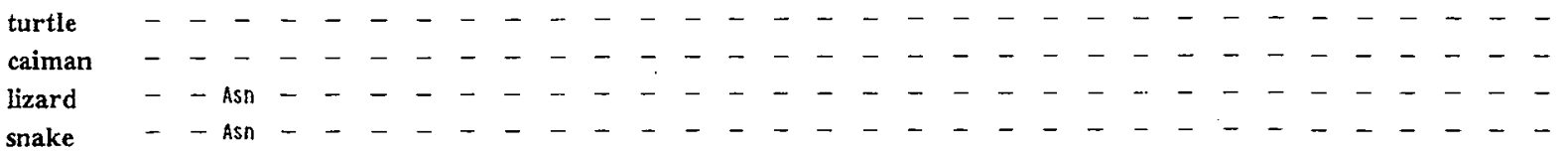

Fig. 2. Nucleotide sequences (A) and amino acid sequences (B) predictable from reptile PCR products. The nucleotide sequence and the amino acid sequence of chicken calcitonin are also shown for comparison. Horizontal bars indicate identical bases and amino acid residues to the chicken calcitonin.

four nucleotides differ at positions $8,9,15$ and 25 , only the 3 rd amino acid residue differs from chicken. In turtle (sequence identity, $100 \%$ ), the nucleotide sequences obtained from the PCR and RT-PCR methods completely coincided with that of the chicken calcitonin.

\section{DISCUSSION}

Table 1 shows the sequence identity of the amino acid residues of reptile calcitonins to those of other vertebrates. The similarity of reptile calcitonins is $77 \%$ to the stingray of cartilaginous fish, $84-97 \%$ to bony fish, $69 \%$ to the bullfrog of anuran amphibians, $97-100 \%$ to the chicken of birds, and $34-$ $53 \%$ to mammals. Thus, it is clear that reptile calcitonins are highly homologous to chicken calcitonin, and are never intermediate phylogenetically between amphibians and birds. The

Table 1. Sequence identity of amino acid residues of calcitonins among reptiles, ray, bony fishes, frog, chicken and mammals.

\begin{tabular}{lcccc}
\hline & turtle & caiman & lizard & snake \\
\hline ray & 78 & 78 & 75 & 75 \\
\hline salmon & 84 & 84 & 88 & 88 \\
eel & 94 & 94 & 97 & 97 \\
goldfish & 94 & 94 & 91 & 91 \\
sardine & 84 & 84 & 88 & 88 \\
\hline frog & 69 & 69 & 69 & 69 \\
\hline chicken & 100 & 100 & 97 & 97 \\
\hline rat & 50 & 50 & 53 & 53 \\
rabbit & 47 & 47 & 50 & 50 \\
human & 47 & 47 & 50 & 50 \\
canine & 47 & 47 & 50 & 50 \\
porcine & 34 & 34 & 38 & 38 \\
bovine & 34 & 34 & 38 & 38 \\
ovine & 38 & 38 & 41 & 41 \\
\hline
\end{tabular}

Data from Sasayama et al. (1993), Yoshida et al. (1997) and this study. number of reptile hormones of which the primary structure has been clarified, is not so many at present. However, the amino acid sequence of the $\alpha$-subunit of insulin of the red ear turtie and alligator coincides completely with that of the chicken (Conlon and Hicks, 1990). Recently, amino acid sequences of growth hormone and prolactin of the sea turtle were determined (Yasuda et al., 1989, 1990). The sequence identity of the amino acid residues of those hormones between sea turtle and other vertebrates is $32-35 \%$ to bony fish, $66-75 \%$ to amphibians, $85-88 \%$ to birds, and $58-88 \%$ to mammals (Rand-Weaver et al., 1993). Furthermore, the amino acid sequence of luteinizing hormone (LH) of sea turtle was reported (Koide et al., 1995). The sequence identity of $\alpha$-subunit of the turtle $\mathrm{LH}$ to that of chicken was high, $95-98 \%$, in contrast to the $70-80 \%$ homology to other vertebrate groups. Therefore, also in these hormones, a high homology is recognized between reptiles and birds. Although studies of the morphology of the temporal fossa of the skull (Frazzetta, 1968; Radinsky, 1987 ) and of the 12S and 16S ribosomal RNA of mitochondria (Hedges, 1994) show that birds are closely related to reptiles, this relationship may be supported also.from hormonal aspects.

Furthermore, in this study, sequence identity of the amino acid residues of the turtle calcitonin was $100 \%$ the same to chicken calcitonin. According to the usual taxonomy, turtles are primitive reptiles and belong to a different lineage from other reptiles because of the peculiar morphology of the skull (Colbert and Morales, 1991). Recentiy, however, it was reported that turtles are affinities to other reptiles, and not so different, on the bases of cladistic analysis using 168 characters (Rieppel and deBraga, 1996). Therefore, the results obtained in this study seem not to contradict to the reptile phylogeny.

On the other hand, in both reptiles and birds, the physiological role of calcitonin in adults is not clear (Dacke, 1979). In the chick, however, calcitonin has been suggested to function to prevent hypercalcemia when calcium moves from the 
eggshell for the rapidly growing skeleton in the egg (Baimbridge and Taylor, 1980), and to regulate the acid-base balance of the blood by calcium carbonate (Taylor et al., 1975). In fact, the blood calcitonin levels and calcitonin contents of the ultimobranchial gland of chicks are higher in individuals just before and just after hatching, compared to the adult levels (Dacke, 1979). Also in snakes, the calcitonin contents of the ultimobranchial gland are higher in hatchlings than those of the adults (Uchiyama et al., 1981). Only the ultimobranchial glands at the stages around the hatching in snakes react intensely with calcitonin antiserum in immunohistochemistry (Sasayamsa et al., 1990). These facts suggest that the physiological role of calcitonin in reptiles is similar to that of birds.

\section{REFERENCES}

Baimbridge KG, Taylor TG (1980) Role of calcitonin in calcium homeostasis in the chick embryo. J Endocrinol 85: 171-185

Colbert ED, Morales M (1991) Conquest of the land. In "Evolution of Vertebrates" Ed by ED Colbert, M Morales, Wiley-Liss Inc, New York, pp 129-136

Conlon JM, Hicks JW (1990) Isolation and structural characterization of insulin, glucagon and somatostatin from the turtle, Pseudemys scripta. Peptides 11: 461-466

Copp DH, Brooks CE, Low BS, Newsome F, O'dor RK, Parkes CO, Walker V, Watts EG (1970) Calcitonin and ultimobranchial function in lower vertebrates. In "Calcitonin" Ed by S Taylor, Heinemann, London, pp 281-294

Dacke CG (1979) Calcium regulation in reptiles. In "Calciumn Regulation in Sub-mammalian Vertebrates", Academic Press, London, pp147-155

Frazzetta TH (1968) Adaptive problems and possibilities in the temporal fenestration of tetrapod skulls. J Morphol 125: 145-158

Hedges SB (1994) Molecular evidence for the origin of birds. Proc Natl Acad Sci USA 91: 2621-2624

Iwami M, Tanaka A, Hano N, Sakurai S (1996) Bombyxin gene expression in tissues other than brain detected by reverse transcription-polymerase chain reaction (RT-PCR) and in situ hybridization. Experientia 52: 882-887

Koide Y, Papkoff H, Kawauchi H (1995) The complete amino acid sequence of lutropin from a reptile, the sea turtle. Proc Jap Soc Comp Endocrinol 1995: 24

Lasmoles F, Jullienne A, Day F, Minvielle S, Milhaud G, Moukhtar MS (1985) Elucidation of the nucleotide sequence of chicken calcitonin mRNA: direct evidence for the expression of a lower vertebrate calcitonin-like gene in man and rat. EMBO J 4:26032607

Pöschl E, Lindley I, Hofer E, Seifert JM, Brunowsky W, Besemer J (1987) The structure of procalcitonin of the salmon as deduced from its CDNA sequence. FEBS Lett 226: 96-100

Radinsky LB (1987) The Evolution of Vertebrate Design. Univ Chicago Press, Chicago

Rand-Weaver M, Kawauchi H, Ono M (1993) Evolution of the structure of the growth hormone and prolactin family. In "The Endocrinology of Growth, Development, and Metabolism in Vertebrates" Ed by MP Schrebman, CG Scanes, PKT Pang, Academic Press Inc, New York, pp 13-42

Rieppel O, deBraga M (1996) Turtle as diapsid reptiles. Nature 384 : 453-455

Sasayama Y, Yoshihara M, Fujimori M, Oguro C (1990) The role of the ultimobranchial gland in calcium metabolism of amphibians and reptiles. In "Progress in Comparative Endocrinology" Ed by A Epple, CG Scanes, MH Stetson, Wiley-Liss, New York, pp $592-$ 597

Sasayama $Y$, Takagi T, Kase $Y$, Suzuki N, Takei $Y$, Nagasawa $H$, Watanabe TX, Nakajima K (1993) Calcitonin in lower vertebrates. In "Progress in Comparative Endocrinology" Ed by MRP Varavudhi, S Lorlowhakarn, The Asia and Oceania Soc Comp Endocrinol, Chiangmai, pp 29-30

Steenbergh PH, Hoppener JWM, Zandberg J, Visser A, Lips CJM, Jansz HS (1986) Structure and expression of the human calcitonin/CGRP genes. FEBS Lett 209: 97-103

Taylor TG, Balderstone O, Baimbridge KG, Lewis PE (1975) Changes in the concentration of calcium and calcitonin in the plasma of chick embryos during incubation. In "Calcium Regulating Hormone" Ed by RV Talmage, M Owen, JA Parsons, Excerpta Medica, Amsterdam and New York, pp 116-118

Uchiyama M, Yoshihara M, Murakami T, Oguro C (1981) Calcitonin content in the ultimobranchial gland of the snake, Elaphe climacophora; comparison of adults, young, and hatchlings. Gen Comp Endocrinol 43: 259-261

Yasuda A, Yamaguchi K, Papkoff $H$, Yokoo Y, Kawauchi H (1989) The complete amino acid sequence of growth hormone from the sea turtle (Chelonia mydas). Gen Comp Endocrinol 73: 242-251

Yasuda A, Kawauchi $H$, Papkoff $H(1990)$ The complete amino acid sequence of prolactin from the sea turtle (Chelonia mydas). Gen Comp Endocrinol 80: 363-371

Yoshida A, Kaiya H, Takei Y, Watanabe TX, Nakajima K, Sasayama Y, Suzuki N (1997) Primary structure and bioactivity of bullfrog calcitonin. Gen Comp Endocrinol 107: 147-152

(Received January 13, 1997 / Accepted June 9, 1997) 